\title{
ASTHMA
}

\section{Sputum T lymphocytes in asthma, COPD and healthy subjects have the phenotype of activated intraepithelial T cells (CD69+ CD103+)}

\author{
M J Leckie, G R Jenkins, J Khan, S J Smith, C Walker, P J Barnes, T T Hansel
}

See end of article for authors' affiliations

.....................

Correspondence to: Dr T T Hansel, Clinical Studies Unit, Royal

Brompton Hospital, London

SW3 6HP, UK;

t.hansel@ic.ac.uk

Revised version received 1 July 2002

Accepted for publication

2 August 2002
Background: T cells of intraepithelial phenotype have previously been detected in bronchoalveolar lavage (BAL) fluid in a range of lung diseases; these cells express the adhesion molecule $\alpha_{E} \beta_{7}$ integrin, CD 103, the ligand for epithelial cell E-cadherin. In subjects with asthma CD4+ lymphocytes are the predominant T cell subtype found in bronchial biopsy specimens and in BAL fluid, whereas CD8+ lymphocytes have been shown to predominate in subjects with chronic obstructive pulmonary disease (COPD). The aim of this study was to analyse the expression of CD103, activation markers (CD25 and CD69), and chemokine receptors (CXCR3, CCR5 and CCR3) on CD4+ and CD8+ lymphocytes from sputum and peripheral blood of subjects with asthma, COPD, and healthy controls.

Methods: T cell surface markers were assessed by immunofluorescence labelling and flow cytometry of gated lymphocytes among CD45+ leucocytes in sputum cell suspensions.

Results: Sputum lymphocytes expressed higher levels of CD 103 and CD69 than blood lymphocytes in all subject groups, with CD103 expressed at higher levels on CD8+ than on CD4+ cells. There were no detectable differences in numbers of CD4+ and CD8+T cells between subjects with asthma, COPD and controls. The percentage of sputum lymphocytes expressing CXCR3 was lower in subjects with asthma or COPD than in healthy controls; CCR3 was not detectable on sputum or blood lymphocytes. Conclusions: Sputum T lymphocytes are predominantly of activated intraepithelial phenotype $(C D 103+C D 69+)$, and normal numbers of CD4+ and CD8+ T cell populations are found in the sputum of patients with asthma and COPD.
A sthma and chronic obstructive pulmonary disease (COPD) are both obstructive airway disorders, but differing types of inflammation are involved in the pathogenesis of these distinct lung diseases. Asthma is frequently an allergic process with a preponderance of CD4+ T helper type 2 (Th2) cells and eosinophils in the airways. ${ }^{12}$ In contrast, following long term cigarette smoking and the development of COPD, there are excess numbers of CD8 $+\mathrm{T}$ cytotoxic cells, neutrophils, and macrophages in the airways, ${ }^{3}{ }^{4}$ as well as predominant Thl activity in blood. ${ }^{5}$ These differences in $\mathrm{T}$ cell populations have been largely documented in studies using mucosal biopsy specimens and bronchoalveolar lavage (BAL) fluid, while there are relatively few studies on T cells in sputum.

Following the inhalation of nebulised hypertonic saline, sputum can be expectorated by the majority of healthy "normal" subjects as well as patients with lung disease. ${ }^{6}$ Sputum induction is a relatively non-invasive means of obtaining tissue derived cells and, following liquefaction with dithiothreitol (DTT), light microscopy of cytospin samples has been shown to be reliable and reproducible. Flow cytometry has been used in the determination of surface markers on eosinophils ${ }^{7}$ and neutrophils. ${ }^{8}$ Although sputum lymphocytes represent only up to $2 \%$ of the leucocytes in sputum, flow cytometry studies have shown that there is an excess of CD4+ $\mathrm{T}$ cells in asthma, ${ }^{9-11}$ and an increase in B cells has also been described. ${ }^{12}$

Increased percentages of peripheral blood lymphocytes expressing CD25 (interleukin-2 receptor (IL-2R) $\beta$-chain or CD25) are found in patients with acute severe asthma. ${ }^{13}$ Furthermore, increased percentages of CD4+ cells expressing $\mathrm{CD} 25^{12}$ and intracellular adhesion molecule 1 (ICAM- 1$)^{9}$ have been detected by flow cytometry of sputum samples from patients with asthma. It has recently been shown that CD25 is expressed more highly on peripheral blood than on BAL lymphocytes, whereas the opposite was found for CD69. ${ }^{14}$ It has been suggested that CD25 is a marker of $\mathrm{T}$ cell proliferation rather than activation per se, while CD69 may be a better marker of activation. ${ }^{15}$ CD69 can be induced on many different cells including $\mathrm{T}$ cells, macrophages, eosinophils, and neutrophils. ${ }^{16}$

Thl and Th2 cells are thought to differ in their expression of chemokine receptors. In studies on $\mathrm{T}$ cell lines there is evidence to suggest that Th2 type cells express CCR3, CCR4 and CCR8, while CXCR3 and CCR5 may be expressed preferentially by Thl type cells. ${ }^{17}{ }^{18}$ As a consequence of this differential expression of chemokine receptors, possibly combined with variations in adhesion molecule expression, ${ }^{19}{ }^{20} \mathrm{Th} \mathrm{l}$ and Th2 cells may be selectively recruited to the airways in COPD and asthma, respectively.

Sputum T cells have generally migrated through the respiratory epithelium and have the potential to express adhesion molecules that reflect this prior interaction with epithelial cells. The intraepithelial lymphocyte (IEL) adhesion molecule CD103 (or $\alpha_{\mathrm{E}} \beta_{7}$ integrin) binds to E-cadherin on epithelial cells. ${ }^{21}$ Epithelial cells produce transforming growth factor $\beta$ (TGF- $\beta$ ) that promotes expression of lymphocyte $\alpha_{\mathbb{E}} \beta_{7}$ and the long term survival of IELs that may function as a pool of memory cells primed to respond rapidly to antigens, ${ }^{22}$ although $\alpha_{\mathrm{E}}$ is not associated with mucosa specific homing of lymphocytes. ${ }^{23}$ Significant upregulation of $\alpha_{\mathrm{E}} \beta_{7}$ has been found predominantly on BAL CD8 $+\mathrm{T}$ cells in allergic asthma and other lung diseases ${ }^{24}$ as well as in healthy volunteers. ${ }^{25}$

We have used immunofluorescence labelling and flow cytometry to assess $\mathrm{T}$ lymphocyte surface markers in sputum from patients with asthma and COPD. In particular, we aimed to 
Table 1 Clinical characteristics of study subjects

\begin{tabular}{|c|c|c|c|}
\hline & $\begin{array}{l}\text { Healthy non-atopic } \\
\text { controls }(n=6)\end{array}$ & Asthma $(n=8)$ & COPD $(n=7)$ \\
\hline Age (years) & $31.1(1.2)$ & $30.9(2.2)$ & $63.1(4.2)$ \\
\hline $\operatorname{Sex}(F / M)$ & $4 / 2$ & $5 / 3$ & $0 / 8$ \\
\hline $\mathrm{FEV}_{1}$ (\% predicted) & $96.6(4.1)$ & $90.8(4.5)$ & $55.1(5.9)$ \\
\hline $\mathrm{PC}_{20}(\mathrm{mg} / \mathrm{ml})$ & N/A & $1.4(0.5)$ & N/A \\
\hline Current smokers (\%) & 0.0 & 0.0 & 62.5 \\
\hline Pack years & 0.0 & 0.0 & $52.6(5.3)$ \\
\hline $\mathrm{FEV}_{1} / \mathrm{FVC}$ ratio & $77.8(3.6)$ & 87.7 (3.3) & $55.5(5.9)$ \\
\hline Drugs & $\mathrm{Nil}$ & $\beta_{2}$ agonist $\times 1 /$ week & $\begin{array}{l}3 \text { nil, } 1 \beta_{2} \text { agonist only, } 3 \text { on } \\
>400 \mu \mathrm{g} \text { BDP }\end{array}$ \\
\hline
\end{tabular}

Results expressed as mean (SE)

$\mathrm{FEV}_{1}=$ forced expiratory volume in 1 second; $\mathrm{FVC}=$ forced vital capacity; $\mathrm{PC}_{20}=$ concentration provoking a fall

in $\mathrm{FEV}_{1}$ of $20 \%$ or more; $\mathrm{N} / \mathrm{A}=$ not applicable.
.

identify CD4+ and CD8+ lymphocytes and assess the expression of surface markers of activation (CD25, CD69), chemokine receptors (CXCR3, CCR3, and CCR5), and adhesion molecules (CD103) to establish the phenotype of sputum T cells in terms of Th1 or Th2, cytotoxic and intraepithelial populations.

\section{METHODS}

\section{Study populations}

Six healthy non-smoking subjects with normal lung function and no history of atopy and eight non-smoking patients with mild allergic asthma treated with $\beta_{2}$ agonists were included in the study. The subjects with asthma had symptoms requiring a $\beta_{2}$ agonist no more frequently than every two days, and all of them had a histamine $\mathrm{PC}_{20}<2.5 \mathrm{mg} / \mathrm{ml}$ (table 1 ). In addition, seven patients with a history of $>20$ pack years cigarette smoking, air flow limitation that was not fully reversible as defined by recent Global Obstructive Lung Disease (GOLD) criteria (post-bronchodilator forced expiratory volume in 1 second $\left(\mathrm{FEV}_{1}\right)<80 \%$ with a post-bronchodilator ratio of $\mathrm{FEV}_{1}$ to forced vital capacity (FVC) of $<70 \%$ ) were recruited prospectively into the study. All seven patients with COPD had improvement in $\mathrm{FEV}_{1}$ of $<12 \%$ following inhalation of salbutamol on the date of sputum induction and blood sampling. None of the subjects in any of the groups had a viral infection in the two weeks before sputum induction. Patients were asked to withhold bronchodilator therapy for at least 8 hours before sputum induction.

All subjects gave written informed consent for participation and the study was approved by the ethics committee of the Royal Brompton and Harefield Hospital National Health Service Trust.

\section{Sputum induction}

Before sputum induction all patients inhaled salbutamol $(200 \mu \mathrm{g})$ via a metered dose inhaler. Baseline $\mathrm{FEV}_{1}$ was measured and this was repeated following salbutamol and after each 5 minute inhalation of nebulised hypertonic saline $(3.5 \%)$. The procedure was stopped if the FEV fell by $>10 \%$ following saline or by $>20 \%$ at any time during the induction procedure.

\section{Sputum processing}

Solid sputum material was separated from saliva before processing. ${ }^{9}$ Briefly, selected sputum was weighed and $0.1 \%$ DTT (Sigma-Aldrich, Poole, UK) in phosphate buffered saline (PBS) was added at a ratio of $4 \mathrm{ml}$ to $1 \mathrm{~g}$ sputum. The sputum was incubated with DTT at room temperature for 15 minutes on a rolling mixer. The same volume ( $4 \mathrm{ml}$ to $1 \mathrm{~g}$ sputum) of PBS was added to the sputum and then filtered through $48 \mu \mathrm{m}$ nylon gauze. The filtrate was centrifuged at $400 \mathrm{~g}$ (Sorvall RT6000D, Kendro, Bishop's Stortford, UK) for 10 minutes at $4^{\circ} \mathrm{C}$ to pellet cells. The cells were resuspended in PBS containing $0.1 \%$ bovine serum albumin (BSA). The viability of the sample was determined by trypan blue exclusion staining (Sigma-Aldrich) in a Neubauer haemocytometer (Merck Eurolabs, Lutterworth, UK). Cytospins of sputum cells that were used for determination of differential cell counts were fixed with methanol and stained with May-Grunwald-Giemsa stain (Merck-Eurolabs).

\section{Flow cytometry of sputum cells}

Sputum cells were washed in Dulbecco's PBS containing 0.1\% sodium azide (Sigma-Aldrich) and 0.4\% BSA (Sigma-Aldrich) $(\mathrm{PAB})$ and centrifuged at $400 \mathrm{~g}$. The cells were resuspended in PAB at $2 \times 10^{6}$ cells $/ \mathrm{ml}$. For each test, sputum cell suspension $(90 \mu \mathrm{l})$ was incubated with antibody $(5 \mu \mathrm{l})$ for 45 minutes at $4^{\circ} \mathrm{C}$ in the dark. Cells were then washed with PAB, resuspended in CellFix (Becton Dickinson, Cowley, UK) and subsequently analysed using a FACSCalibur flow cytometer (Becton Dickinson). Up to 70000 total events were collected per sample. The lymphocyte population was then delineated on their physical characteristics in a region according to their characteristic forward scatter (FSC) and side scatter (SSC) profile.

All sputum cell samples were stained with a PE-Cy5 conjugated anti-human CD45 monoclonal antibody (Dako, Ely, UK) to exclude, by logical gating, all non-leucocyte events in each test. To obtain a CD4+:CD8+ ratio, cells were stained with fluorescein isothiocyanate (FITC) conjugated anti-human CD4 and phycoerythrin (PE) conjugated anti-human CD8 in the same test tube. To assess surface marker expression samples were incubated with either FITC conjugated anti-human CD69, FITC conjugated anti-human CDl03 (Dako), FITC conjugated anti-human CXCR3, FITC conjugated anti-human CCR3 (R\&D Systems, Abingdon, UK), or PE conjugated antihuman CCR5 (Pharmingen, San Diego, USA) in combination with either FITC or PE conjugated anti-human CD4 or anti-human CD8. PE or FITC conjugated matched isotype antibodies served as controls. The number of positive cells for each surface marker was expressed as a percentage of the $\mathrm{CD} 4+$ or $\mathrm{CD} 8+$ positive cells.

\section{Flow cytometry of whole blood}

Fresh whole blood ( $90 \mu \mathrm{l}$ in EDTA) was incubated with $5 \mu \mathrm{l}$ of each antibody for 45 minutes at $4^{\circ} \mathrm{C}$ in the dark. The sputum antibody staining strategy was also used for blood cells, with the exception that the anti-human CD45 monoclonal antibody was not used. Erythrocytes were lysed using 2 ml FACSlyse (Becton Dickinson) for 20 minutes and washed in PAB. Lymphocyte events were gated on the characteristic FSC and SCC only. For each test, 100000 total events were collected.

\section{Data analysis}

Flow cytometry data were acquired and analysed using CellQuest Software (Becton Dickinson). The significance of the difference between blood and sputum was tested using a 


\begin{tabular}{|c|c|c|c|}
\hline & $\begin{array}{l}\text { Healthy } \\
\text { controls }(n=6)\end{array}$ & $\begin{array}{l}\text { Asthma } \\
(\mathrm{n}=8)\end{array}$ & $\begin{array}{l}\text { COPD } \\
(n=7)\end{array}$ \\
\hline \multicolumn{4}{|l|}{ Cytospins } \\
\hline Total cells $\left(10^{6}\right)$ & $27.19(20.90)$ & $13.75(2.60)$ & $52.78(17.78$ \\
\hline Macrophages (\%) & $55.17(9.80)$ & 30.87 (12.74) & $25.41(4.52)$ \\
\hline Neutrophils (\%) & $44.10(9.88)$ & $67.40(11.98)$ & 70.86 (3.84) \\
\hline Eosinophils (\%) & $0.43(0.21)$ & $1.37(0.42)$ & 3.59 (1.59) \\
\hline Lymphocytes (\%) & $0.30(0.10)$ & $0.36(0.21)$ & $0.15(0.10)$ \\
\hline \multicolumn{4}{|l|}{ Flow cytometry } \\
\hline CD4 lymphocytes (\%) & $2.01(1.32)$ & $1.55(0.75)$ & $0.97(0.30)$ \\
\hline CD8 lymphocytes (\%) & $0.42(0.15)$ & $0.28(0.11)$ & $0.38(0.14)$ \\
\hline CD4:CD8 ratio & $4.90(1.58)$ & $5.49(1.16)$ & $2.79(0.96)$ \\
\hline
\end{tabular}

Results are expressed as mean (SE).

Wilcoxon signed rank test, and the differences between the groups were compared using a Wilcoxon rank sum test. A value of $p<0.05$ was considered significant.

\section{RESULTS}

There were significant differences in the percentages of sputum neutrophils $(p=0.045)$, macrophages $(p=0.032)$, and eosinophils $(p=0.044)$ as assessed by light microscopy between patients with COPD and healthy non-atopic controls (table 2). The percentages of neutrophils and eosinophils were both increased and the percentages of macrophages were decreased in subjects with COPD compared with healthy controls. There were no significant differences in the percentages of any of the sputum cell types between subjects with asthma and healthy controls. The subjects with COPD were moderate to severe, while the patients with asthma were very mild. The mild severity of the asthmatic subjects may account for the lack of difference in the sputum cell differentials between the healthy controls and the asthma group. In all subjects the cell viability exceeded $80 \%$. Successful sputum induction was achieved in all patients.

Representative flow analysis plots and histograms of CD4:CD8 staining of sputum lymphocytes, CXCR3 staining of CD4+ blood cells, and CD69 and CD103 staining in CD8+ sputum cells are shown in fig 1.

There were no significant differences in the CD4+:CD8+ ratio in sputum between the three subject groups, nor were there any differences in the percentages of blood or sputum CD4+ or CD8+ lymphocytes between the groups (table 2). In normal control subjects and patients with asthma there was a significantly higher $\mathrm{CD} 4+: \mathrm{CD} 8+$ ratio in sputum than in blood (healthy controls $p=0.007$; asthma patients $p=0.005$ ). There was no such increase in the CD4:CD8 ratio in sputum compared with blood in patients with COPD.

In the study to assess the effects of DTT on cell markers, no differences were seen in staining of any of the cell surface markers (CXCR3, CCR5, CCR3, CD69 or CD103) on either $\mathrm{CD} 4+$ or CD8 + cells between samples pretreated with DTT and those treated with buffer alone (table 3 ).

B CD4+ blood lymphocytes

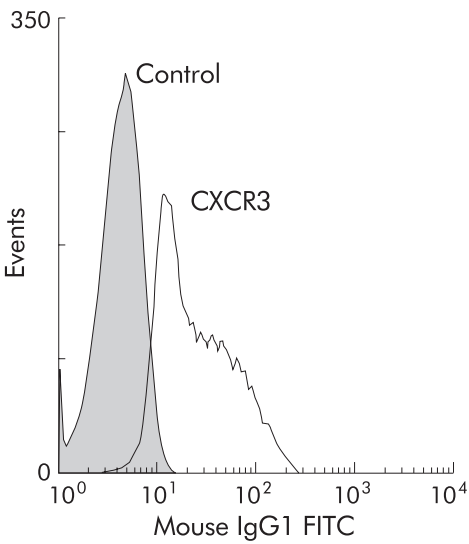

D CD8+ sputum lymphocytes

C CD8+ sputum lymphocytes

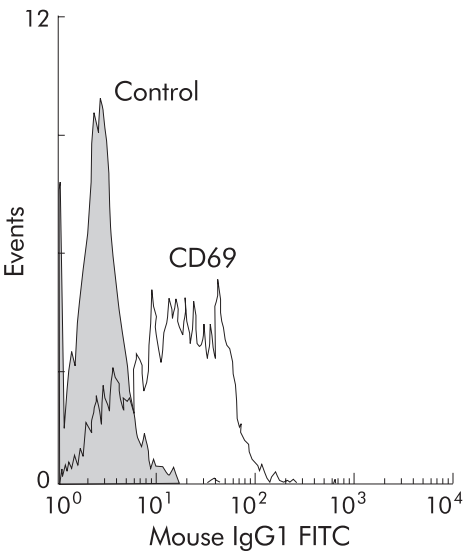

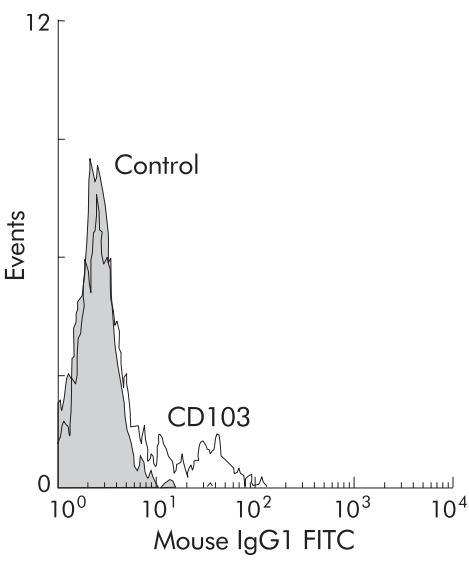

Figure 1 Representative plot and histograms showing (A) CD8 (FITC) and CD4 (PE) staining of sputum lymphocytes among a population of CD45+ cells gated on physical characteristics; (B) CXCR3 staining of CD4+ lymphocytes in blood, (C) CD69 staining of CD 8+ lymphocytes in sputum, and (D) CD103 staining of CD8+ lymphocytes in sputum. 
Table 3 The effects of dithiothreitol (DTT) on percentage of sputum lymphocytes (CD4+ and CD8+) expressing CXCR3, CCR5, CCR3, CD69 and CD103

\begin{tabular}{|c|c|c|c|c|c|c|}
\hline & \multicolumn{3}{|l|}{$\mathrm{CD} 4+$} & \multicolumn{3}{|l|}{ CD8+ } \\
\hline & No DTT (\%) & DTT (\%) & $\mathrm{p}$ value & No DTT (\%) & DTT (\%) & $\mathrm{p}$ value \\
\hline CXCR3 & $35.1(1.7)$ & $39.5(6.2)$ & NS & $47.2(6.1)$ & 46.9 (6.1) & NS \\
\hline CCR5 & $12.4(0.9)$ & $16.0(4.0)$ & NS & 31.4 (11.1) & $31.8(10.6)$ & NS \\
\hline CCR3 & $1.0(0.2)$ & $1.2(0.5)$ & NS & $1.6(0.9)$ & $4.4(2.7)$ & NS \\
\hline CD69 & $2.5(0.6)$ & $3.4(0.8)$ & NS & $5.6(1.0)$ & $5.2(0.4)$ & NS \\
\hline CD103 & $1.2(0.2)$ & $1.4(0.1)$ & NS & $3.2(0.9)$ & $3.3(0.9)$ & NS \\
\hline
\end{tabular}
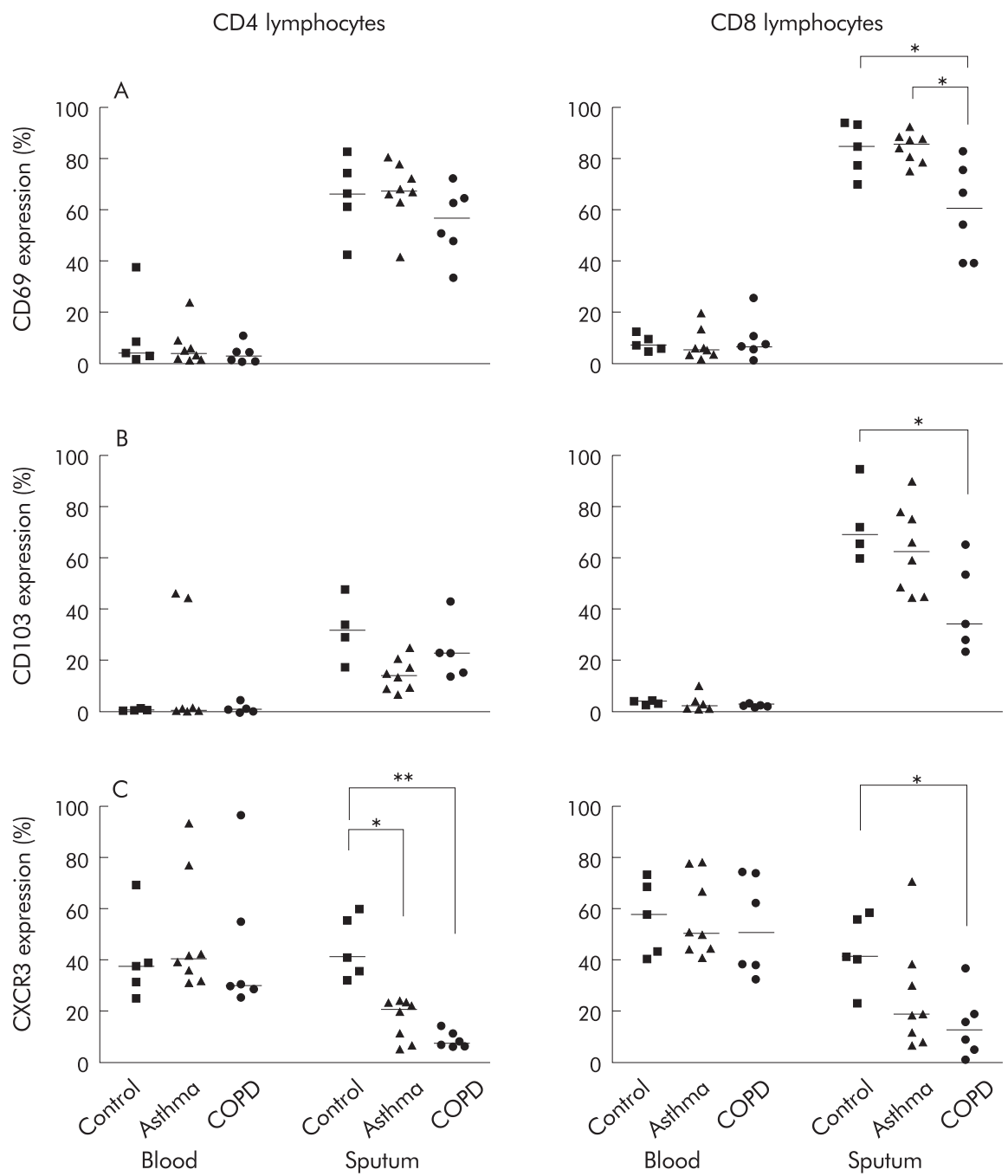

Figure 2 Blood and sputum CD4+ and CD8+ lymphocyte expression of surface markers. (A) CD69, (B) CD103 and (C) CXCR3 in peripheral blood and in sputum cell suspensions from subjects with asthma (triangles), COPD (circles), and healthy controls (squares). The median value of each dataset is represented by a horizontal bar. ${ }^{*} p<0.05 ;{ }^{* *} p<0.01$.

In sputum the percentage of CD8+ lymphocytes from subjects with COPD expressing CD69 (60.3\% (95\% CI 38.8 to 82.4) was significantly lower than from healthy subjects $(84.4 \%$ (95\% CI 69.6 to 93.8), $\mathrm{p}=0.029$ ) and subjects with asthma (85.6\% (95\% CI 75.0 to 92.2), $\mathrm{p}=0.010$ ). CD8+ lymphocytes in the asthma and healthy control groups had higher percentages of CD69 expression than CD4+ cells. In the COPD group the percentages of sputum CD4+ and CD8+ lymphocytes expressing CD69 were similar. In all groups there were higher percentages of both sputum CD4+ and CD8 + cells expressing CD69 than peripheral blood lymphocytes (CD4+: healthy control group, $\mathrm{p}=0.008$; asthma, $\mathrm{p}<0.001$; COPD, $\mathrm{p}=0.002$; CD8+: healthy control group, $\mathrm{p}<0.001$; asthma, $\mathrm{p}<0.001$; COPD, $\mathrm{p}=0.001$; fig $2 \mathrm{~A}$ ).

The expression of CD25 was only assessed in subjects with COPD. The percentages of both CD4+ and CD8+ lymphocytes expressing CD25 were lower than CD69 in the sputum samples (fig 3). The percentage expression of CD25 was significantly greater for CD4+ sputum lymphocytes than for CD4+ lymphocytes in peripheral blood $(p<0.04)$. There was no difference in the expression of CD25 on CD8+ cells from blood and sputum. 


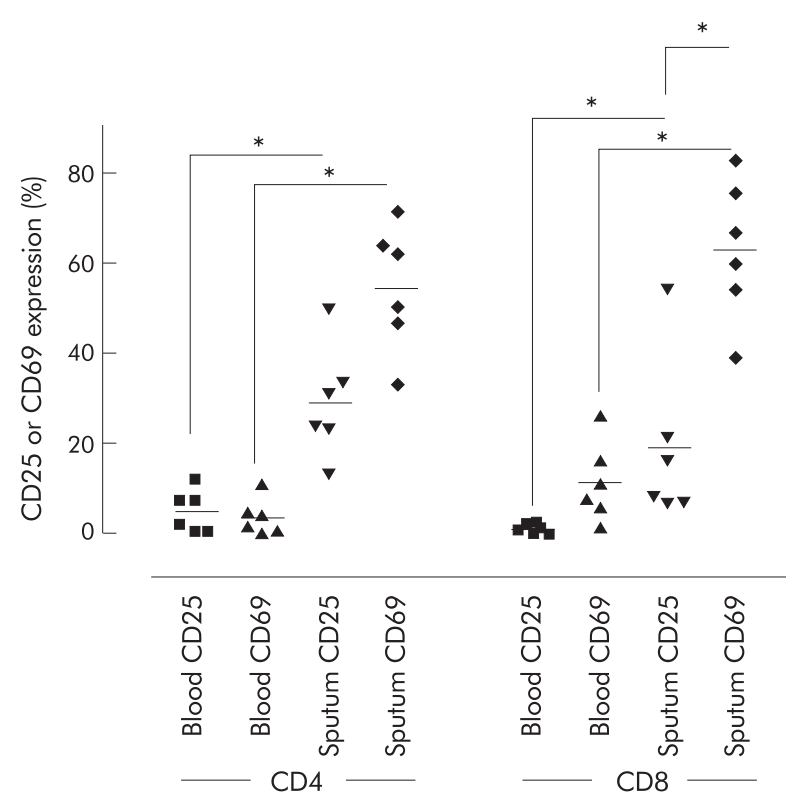

Figure 3 Blood and sputum CD4+ and CD8+ lymphocyte expression of CD25 and CD69 in subjects with COPD. CD4/CD25 or CD8/CD25 (squares); CD4/CD69, CD8/CD69 (triangles); CD4/CD25 and CD8/CD25 (inverted triangles); CD4/CD69 and CD8/CD69 (diamonds). The median value of each dataset is represented by a horizontal bar. ${ }^{*} p<0.05$.

In sputum the percentage of cells expressing IEL marker $\alpha_{\mathrm{E}} \beta_{7}, \mathrm{CD} 103$, was higher for CD8 + cells than for CD4+ cells in all groups. The percentages of CD8+ sputum lymphocytes that expressed CDI03 was significantly lower in subjects with COPD than in the normal control group $(p=0.028)$. In all subject groups there was a higher percentage of CD8+ lymphocytes expressing $\mathrm{CD} 103$ in sputum than in blood (healthy control group, $\mathrm{p}=0.003$; asthma, $\mathrm{p}<0.001$; COPD, $\mathrm{p}=0.009$ ). The same increase in the percentage of CD4+ lymphocytes that expressed CD103 in sputum compared with blood was observed for the healthy control group $(p=0.016)$ and the COPD group ( $p=0.015$; fig $2 B$ ).

The percentage expression of both CD4+ and CD8+ lymphocytes expressing CXCR3 was reduced in the sputum of subjects with COPD (CD4+ cells: $7.0 \%$ (95\% CI 5.7 to 13.3), CD8+ cells: $10.9 \%$ (95\% CI 0.7 to 35.5 ) compared with the healthy control group (CD4+ cells: $40.8 \%$ (95\% CI 31.9 to 59.6), $\mathrm{p}=0.009$; CD8+ cells: $39.3 \%$ (95\% CI 21.7 to 57.3 ), $\mathrm{p}=0.018)$. In addition, the percentage of CD4+ lymphocytes expressing CXCR3 in sputum from subjects with asthma was significantly lower than in normal subjects (asthma 20.4\% (95\% CI 4.6 to 23.8 ); normal $40.8 \%$ (95\% CI 31.9 to 59.6 ), $\mathrm{p}=0.028$ ). The percentage of both CD4+ and CD8+ lymphocytes expressing CXCR3 was lower in sputum than in blood from patients with asthma (CD4; $p=0.003$; CD8 $\mathrm{p}=0.002)$; this was also found for CD8+ lymphocytes in subjects with COPD $(p=0.005$; fig $2 \mathrm{C})$. However, there was no significant difference between the percentages of either CD4+ or CD8 + lymphocytes in sputum and peripheral blood expressing CXCR3 in the healthy control group.

In all groups CD4+ and CD8 + cells expressed CCR5 in both blood and sputum, but there were no significant differences between the groups (data not shown). The expression of the Th2 chemokine receptor CCR3 was negligible and was not increased on CD4+ or CD8+ T lymphocytes in the sputum or blood from asthmatic subjects compared with the normal group (data not shown).

\section{DISCUSSION}

This study shows that in subjects with asthma, COPD and in healthy controls, sputum $\mathrm{T}$ cells have the phenotype of intraepithelial lymphocytes (IELs) in expressing $\alpha_{\mathbb{E}} \beta_{7}$ integrin (CD103). These sputum IEL-type cells may be long lived memory $\mathrm{T}$ cells and may be distinct from the CD4+ and CD8+ $\mathrm{T}$ cells seen in bronchial mucosal biopsy specimens from patients with asthma and COPD. Indeed, in terms of $\alpha_{\mathrm{E}} \beta_{7}$, sputum $\mathrm{T}$ cells resemble intraepithelial and BAL T cells, but may be a differing population from subepithelial tissue $\mathrm{T}$ cells. These cells may function as long term memory cells in allergic responses, ${ }^{2627}$ as well as in immune responses to mycobacteria. ${ }^{28}$ It has been shown that BAL CD8+ lymphocytes and, to a lesser extent, CD4+ lymphocytes, but not blood lymphocytes, have significant expression of $\alpha_{\sharp} \beta_{7} \cdot{ }^{25}$ The increased CD103 expression on sputum CD8 + cells compared with CD4+ cells is in accordance with other reports. ${ }^{29} 30$

$\mathrm{T}$ cells in sputum from patients with COPD, but not those with asthma, showed reduced levels of CD69, CXCR3, and CD103 expression on CD8 + cells compared with normal sputum. The downregulation of these receptors may relate to a loss of them during activation, chemotaxis, and homing of $\mathrm{T}$ cells. Inflammation may contribute to this shedding since tumour necrosis factor $\alpha$ (TNF- $\alpha$ ) has been shown to cause a downregulation of CXCR2 in human neutrophils. ${ }^{31}$ Furthermore, the subjects with COPD used in this study were moderate to severe, while the patients with asthma were very mild requiring inhaled $\beta_{2}$ agonist only once per week on average. These differences in severity may account for the discrepancy in the two patient groups. The differences observed between the surface marker expression of the Tlymphocytes from subjects with COPD and those from healthy controls and subjects with asthma may be attributed to the inflammation associated with COPD. However, the effect on these results of the increased age of the COPD subjects compared with the healthy control subjects and those with asthma cannot be excluded. It has been reported that there are increased percentages of CD8 + cells in bronchial tissue of patients with COPD $^{32}{ }^{33}$ as well as Thl activity in blood. ${ }^{5}$ However, although we investigated COPD patients with a similar disease severity, we did not observe an increased percentage of CD8+ lymphocytes or a decrease in the $\mathrm{CD} 4+: \mathrm{CD} 8+$ ratio in the sputum of these subjects. Induced sputum cells predominantly come from the upper and middle airways, ${ }^{11}$ while lavage represents cells from the bronchoalveolar compartment. Furthermore, CD8+ cells in the lung parenchyma may be localised by adhesion molecules and chemokines, and may not be discharged to the sputum compartment.

We have shown that the percentage of CD8+ cells expressing CD69 was higher than that of the CD4+ cells in the healthy controls and in those with asthma in both peripheral blood and sputum. One possible explanation for this is that CD8 + cells may be preferentially activated. Indeed, there is some recent evidence to suggest that CD8 + cells are functionally active in cultured whole blood from patients with asthma, with increased production of interferon $\gamma^{34}$ We found negligible expression of the purported Th2 chemokine receptor CCR3 on sputum lymphocytes from any of the subjects tested. It has also recently been shown by immunohistochemistry that $\mathrm{T}$ lymphocytes in the bronchial mucosa of allergic asthmatic subjects did not express CCR $3 .^{35}$ In support of these findings, recent evidence now questions the relationship between chemokine receptor expression and phenotype of $\mathrm{T}$ cells. The expression of chemokine receptors has been analysed previously using cell lines and clones which have been polarised by mitogens and cytokines. IL-2, for example, has been shown to cause the preferential expression of CXCR3 and CCR5. ${ }^{36}$ It is therefore possible that the conditions in which cells are cultured can influence their cell surface molecule expression and phenotype. Isolated peripheral blood mononuclear cells from patients with atopic dermatitis have been shown to express CCR4 more highly and CXCR3 to a reduced level than normal subjects, but no differences were found in CCR3 or CCR5 expression. ${ }^{37}$ In contrast, a recent report has 
shown that, in memory $\mathrm{T}$ cells $(\mathrm{CD} 4+, \mathrm{CD} 45 \mathrm{RO}+)$, there were no significant differences between the expression of chemokine receptors CXCR3, CXCR4, CCR3 and CCR5 in cells expressing Thl versus Th2 cytokines. ${ }^{38}$

CCR3 and other Th2 type chemokine receptors may be transiently expressed on T cells. For instance, CCR3 expression can be downregulated within 6 hours of stimulation of the T cell receptor (TCR). ${ }^{39}$ In addition, inflammatory cytokines such as TGF- $\beta$ can inhibit CCR3 expression in Th2 polarised cells. ${ }^{17}$ CCR3 may therefore not be a good marker of $\mathrm{T}$ cell polarisation in vivo. Furthermore, chemokine receptor expression is a dynamic feature of Thl and Th2 cells in vivo and therefore may not be adequate surrogate markers of these cell types. ${ }^{33}$ However, the subjects in the asthmatic group did not have significantly increased numbers of sputum eosinophils compared with the healthy control group. This is probably because the patients had mild intermittent asthma; more severe disease would have more eosinophils. ${ }^{40}$

The possibility that the procedure of sputum processing may have caused a reduction in the amount of chemokine receptor expression was assessed by adding the same concentration of DTT as used in the sputum processing protocol to whole blood from four non-atopic subjects. There is evidence to suggest that anti-oxidants downregulate both CCR2 and CCR5 on human monocytes, ${ }^{41}$ and the possibility exists that the use of DTT may lead to the downregulation of the cell surface receptors examined in our study. We found no evidence of differential receptor expression in whole blood treated with and without DTT, suggesting that the low levels of expression of some of the chemokine receptors in sputum could not be attributed to the effects of DTT. Other studies have also shown that DTT has no effect on the expression of certain surface markers on sputum cells. ${ }^{42}$

We have shown that it is possible to analyse mixed cell populations in sputum samples for lymphocyte cell surface markers, including an activation marker, an intraepithelial adhesion molecule, and three chemokine receptors. In this preliminary study we have not been able to demonstrate convincing imbalances in CD4, CD8, Th1, or Th2 populations in asthma or COPD. However, chemokine receptor expression may vary rapidly on activation, and may not be specific in terms of $\mathrm{CD} 4+/ \mathrm{CD} 8+$ or $\mathrm{Th} 1 / \mathrm{Th} 2$ populations. In contrast, CD69 and CDl03 were found to be useful as markers of activated sputum intraepithelial lymphocytes. Further studies are required on the function of IELs and T cell subpopulations in different compartments of the lung in health and disease.

\section{ACKNOWLEDGEMENTS}

We thank Ms Jackie Turner for help with the statistical analyses.

\section{Authors' affiliations}

M J Leckie, G R Jenkins, J Khan, T T Hansel, National Heart and Lung Institute (NHLl) Clinical Studies Unit, Imperial College, London, UK

S J Smith, P J Barnes, Department of Thoracic Medicine, NHLI, Imperial College School of Medicine, London, UK

C Walker, Novartis Horsham Research Centre, Horsham, Surrey, UK

\section{REFERENCES}

1 Robinson DS, Hamid Q, Ying S, et al. Predominant Th2-like

bronchoalveolar T-lymphocyte population in atopic asthma. N Engl J Med 1992;326:298-304.

2 Romagnani S. The role of lymphocytes in allergic disease. J Allergy Clin Immunol 2000;105:399-408.

3 Lams BEA, Sousa AR, Rees PJ, et al. Immunopathology of the small-airway submucosa in smokers with and without chronic obstructive pulmonary disease. Am J Respir Crit Care Med 1998;158:1518-23.

4 Fournier M, Lebargy F Le Roy, Ladurie F, et al. Intraepithelial T-lymphocyte subsets in the airways of normal subjects and of patients with chronic bronchitis. Am Rev Respir Dis 1989;140:737-42.
5 Maiori M, Corradi M, Caminati A, et al. Predominant THl cytokine pattern in peripheral blood from subjects with chronic obstructive pulmonary disease. J Allergy Clin Immunol 1999;103:458-62.

6 Holz O, Kips J, Magnussen H. Update on sputum methodology. Eur Respir J 2000; 16:355-9.

7 Hansel TT, Braunstein JB, Walker C, et al. Sputum eosinophils from asthmatics express ICAM-1 and HLA-DR. Clin Exp Immunol 1991:86:271-7.

8 In’t Veen JC, Grootendorst DC, Smits HH, et al. CD 11 b and L-selectin expression on eosinophils and neutrophils in blood and induced sputum of patients with asthma compared with normal subjects. Clin Exp Allergy 1998:28:606-12.

9 Louis R, Shute J, Biagi S, et al. Cell infiltration, ICAM-1 expression, and eosinophil chemotactic activity in asthmatic sputum. Am J Respir Crit Care Med 1997; 155:466-72.

10 Grootendorst DC, Sont JK, Willems LNA, et al. Comparison of inflammatory cell counts in asthma:induced sputum vs bronchoalveolar lavage and bronchial biopsies. Clin Exp Allergy 1997;27:769-79.

11 Pizzichini E, Pizzichini M-MM, Kidney JC, et al. Induced sputum, bronchoalveolar lavage and blood from mild asthmatics: inflammatory cells, lymphocyte subsets and soluble markers compared. Eur Respir J $1998 ; 11: 834$.

12 Kidney JC, Wong AG, Efthimiadis A, et al. Elevated B cells in sputum of asthmatics: close correlation with eosinophils. Am J Respir Crit Care Med 1996;153:540-4.

13 Corrigan CJ, Hartnell A, Kay AB. T lymphocyte activation in acute severe asthma. Lancet 1988;i: 1129-32.

14 Ekberg-Jansson A, Arva E, Nilsson O, et al. A comparison of the expression of lymphocyte activation markers in blood, bronchial biopsies and bronchoalveolar lavage: evidence for an enrichment of activated T lymphocytes in the bronchoalveolar space. Respir Med lymphocytes in the b.

15 Mukae H, Kadota J, Kohno S, et al. Increase of activated T-cells in BAL fluid of Japanese patients with bronchiolitis obliterans organizing pneumonia and chronic eosinophilic pneumonia. Chest 1995; 108:123-8.

16 Marzio R, Mauel J, Betz-Corradin S. CD69 and regulation of the immune function. Immunopharmacol Immunotoxicol 1999;21:565-82

17 Sallusto F, Lenig D, Mackay CR, et al. Flexible programs of chemokine receptor expression on human polarised T helper 1 and 2 lymphocytes. $J$ Exp Med 1998;187:875-83

18 Bonecchi R, Bianchi G, Bordignon PP, et al. Differential expression of chemokine receptors and chemotactic responsiveness of type $1 \mathrm{~T}$ helper cells (Th 1s) and Th2s. J Exp Med 1998;187:129-34.

19 Austrup F, Vestweber D, Borges E, et al. P- and E-selectin mediate recruitment of T-helper-1 but not T-helper-2 cells into inflamed tissues. Nature 1997:385:81-3.

20 Springer TA. Traffic signals for lymphocyte recirculation and leukocyte emigration: the multistep paradigm. Cell 1994;76:301-14

21 Cepek KL, Shaw SK, Parker CM, et al. Adhesion between epithelial cells and $\mathrm{T}$ lymphocytes mediated by E- cadherin and the alpha $\mathrm{E}$ beta 7 integrin. Nature 1994;372:190-3.

22 Goto E, Kohrogi H, Hirata N, et al. Human bronchial intraepithelial T lymphocytes as a distinct T-cell subset: their long-term survival in SCID-Hu chimeras. Am J Respir Cell Mol Biol 2000;22:405-1 1

23 Austrup F, Rebstock S, Kilshaw PJ, et al. Transforming growth factor-beta 1 -induced expression of the mucosa- related integrin alpha $E$ on lymphocytes is not associated with mucosa-specific homing. Eur J Immunol 1995;25:1487-91.

24 Rihs S, Walker C, Virchow JC Jr, et al. Differential expression of alpha E beta 7 integrins on bronchoalveolar lavage T lymphocyte subsets: regulation by alpha 4 beta 1 -integrin crosslinking and TGF-beta. Am J Respir Cell Mol Biol 1996;15:600-10.

25 Erle DJ, Brown T, Christian D, et al. Lung epithelial lining fluid T cell subsets defined by distinct patterns of beta7 and betal integrin expression. Am J Respir Cell Mol Biol 1994; 10:237-44.

26 Erle DJ, Pabst R. Intraepithelial lymphocytes in the lung: a neglected lymphocyte population. Am J Respir Cell Mol Biol 2000;22:398-400.

27 de Vries IJ, Langeveld-Wildschut EG, van Reijsen FC, et al. Nonspecific T-cell homing during inflammation in atopic dermatitis: expression of cutaneous lymphocyte-associated antigen and integrin alphaE beta7 on skin-infiltrating T cells. J Allergy Clin Immunol 1997; 100:694-701.

28 Feng CG, Britton WJ, Palendira U, et al. Up-regulation of VCAM-1 and differential expansion of beta integrin-expressing $t$ lymphocytes are associated with immunity to pulmonary Mycobacterium tuberculosis infection. J Immunol 2000;164:4853-60.

29 McFarland RD, Douek DC, Koup RA, et al. Identification of a human recent thymic emigrant phenotype. Proc Natl Acad Sci USA 2000;97:4215-20

30 Van Damme N, De Vos M, Baeten D, et al. Flow cytometric analysis of gut mucosal lymphocytes supports an impaired Th 1 cytokine profile in spondyloarthropathy. Ann Rheum Dis 2001;60:495-9.

31 Asagoe K, Yamamoto K, Takahashi A, et al. Down-regulation of CXCR2 expression on human polymorphonuclear leukocytes by TNF-alpha. $J$ Immunol 1998;160:4518-25.

32 Saetta M, Di Stefano A, Turato G, et al. CD8+ T-lymphocytes in peripheral airways of smokers with chronic obstructive pulmonary disease. Am J Respir Crit Care Med 1998;157:822-6.

33 Saetta $M$, Baraldo S, Corbino L, et al. CD8+ve cells in the lungs of smokers with chronic obstructive pulmonary disease. Am J Respir Crit Care Med 1999;160:711-7.

34 Magnan AO, Mely LG, Camilla CA, et al. Assessment of the TH1/Th2 paradigm in whole blood in atopy and asthma. Am J Respir Crit Care Med 2000;161:1790-6. 
35 Panina-Bordignon $\mathbf{P}$, Mariani M, Fabrizi F, et al. The cell recruitment into human asthmatic airways is dicated by specific chemokine receptors. Am J Respir Crit Care Med 2001;163:A521.

36 Qin S, Rottman JB, Myers P, et al. The chemokine receptors CXCR3 and CCR5 mark subsets of T cells associated with certain inflammatory reactions. J Clin Invest 1998;101:746-54.

37 Yamamoto J, Adachi Y, Onove Y, et al. Differential expression of the chemokine receptors by the Th1- and Th2- type effector populations within circulating CD4+ T cells. J Leukoc Biol 2000;68:568-74.

38 Nanki T, Lipsky PE. Lack of correlation between chemokine receptor and $\mathrm{T}(\mathrm{h}) 1 / \mathrm{T}(\mathrm{h}) 2$ cytokine expression by individual memory T cells. Int Immunol 2000;12:1659-67.
39 Sallusto F, Kremmer E, Palermo B, et al. Switch in chemokine receptor expression upon TCR stimulation reveals novel homing potential for recently activated T cells. Eur J Immunol 1999;29:2037-45.

40 Ackerman V, Marini M, Vittori $E$, et al. Detection of cytokines and their cell sources in bronchial biopsy specimens from asthmatic patients. Relationship to atopic status, symptoms, and level of airway hyperresponsiveness. Chest 1994; 105:687-96.

41 Saccani A, Saccani S, Orlando S, et al. Redox regulation of chemokine receptor expression. Proc Natl Acad Sci USA 2000;97:2761-6.

42 Loppow D, Bottcher M, Gercken G, et al. Flow cytometric analysis of the effect of dithiothreitol on leukocyte surface markers. Eur Respir J $2000 ; 16: 324-9$

\section{LUNG ALERT}

The difficulty in diagnosis of pulmonary embolism

$\Delta$ Chagnon I, Bounameaux H, Aujesky D, et al. Comparison of two clinical prediction rules and implicit assessment among patients with suspected pulmonary embolism. Am J Med 2002;113:337-8

$\mathrm{T}$ o methods of assessing the pre-test probability of pulmonary embolism (PE) are compared in this paper. The Well's score is an established "prediction rule" based on six clinical parameters while the "Geneva score" uses only objective measurements such as age and arterial oxygen tension to assess pre-test risk, both systems attributing patients to low, medium, or high risk groups. However, when clinical judgement disagreed with the objective Geneva score, a third diagnostic strategy-the "Geneva rule with clinical override" — was invoked. Two hundred and seventy seven patients admitted with suspected PE were assessed using the two scoring systems and the diagnosis of PE was made by a combination of D-dimer, venous ultrasonography, helical CT scanning, and pulmonary angiography with a positive diagnosis in 77 cases. The Geneva score overridden by implicit clinical evaluation performed significantly better than either score alone.

Despite developments in diagnostic methodology, the effective diagnosis of PE remains reliant upon the clinical skills of the attending physician.

T M A Wilkinson tomw1970@hotmail.com 